\title{
BMJ Global Health Using critical information to strengthen pandemic preparedness: the role of national public health agencies
}

Mishal S Khan, ${ }^{1,2}$ Osman Dar, ${ }^{3}$ Ngozi A Erondu, ${ }^{1,3}$ Afifah Rahman-Shepherd, ${ }^{1}$ Lara Hollmann (D) , ${ }^{1}$ Chikwe Ihekweazu, ${ }^{4}$ Okechukwu Ukandu, ${ }^{4}$ Emmanuel Agogo, ${ }^{4}$ Aamer Ikram, ${ }^{5}$ Tayyab Razi Rathore, ${ }^{5}$ Ebere Okereke, ${ }^{3}$ Neil Squires ${ }^{3}$

To cite: Khan MS, Dar 0,

Erondu NA, et al. Using critical information to strengthen pandemic preparedness: the role of national public health agencies. BMJ Global Health 2020;5:e002830. doi:10.1136/ bmjgh-2020-002830

Handling editor Seye Abimbola

Received 7 May 2020

Revised 31 July 2020

Accepted 3 August 2020
Check for updates

(c) Author(s) (or their employer(s)) 2020. Re-use permitted under CC BY-NC. No commercial re-use. See rights and permissions. Published by BMJ

${ }^{1}$ Global Health Programme, Chatham House, London, UK ${ }^{2}$ Department of Global Health and Development, London School of Hygiene and Tropical Medicine, London, UK

${ }^{3}$ Public Health England, London, UK

${ }^{4}$ Nigeria Centre for Disease Control, Abuja, Nigeria

${ }^{5}$ National Institute of Health, Islamabad, Pakistan

Correspondence to

Dr Mishal S Khan;

mishal.khan@Ishtm.ac.uk

\section{ABSTRACT}

COVID-19 has demonstrated that most countries' public health systems and capacities are insufficiently prepared to prevent a localised infectious disease outbreak from spreading. Strengthening national preparedness requires National Public Health Institutes (NPHIs), or their equivalent, to overcome practical challenges affecting timely access to, and use of, data that is critical to preparedness. Our situational analysis in collaboration with NPHls in three countries-Ethiopia, Nigeria and Pakistan — characterises these challenges. Our findings indicate that NPHIs' role necessitates collection and analysis of data from multiple sources that do not routinely share data with public health authorities. Since initiating requests for access to new data sources can be a lengthy process, it is essential that NPHIs are routinely monitoring a broad set of priority indicators that are selected to reflect the country-specific context. NPHIs must also have the authority to be able to request rapid sharing of data from public and private sector organisations during health emergencies and to access additional human and financial resources during disease outbreaks. Finally, timely, transparent and informative communication of synthesised data from NPHIs will facilitate sustained data sharing with NPHIs from external organisations. These actions identified by our analysis will support the availability of robust information systems that allow relevant data to be collected, shared and analysed by NPHIs sufficiently rapidly to inform a timely local response to infectious disease outbreaks in the future.

\section{COVID-19 AND THE NEED TO RE-EXAMINE PREPAREDNESS INITIATIVES}

COVID-19 has shown how crippling the human and economic impacts of an infectious disease outbreak can be and demonstrated the extent to which global travel makes all countries susceptible to the rapid spread of pathogens. ${ }^{1}$ Even countries with substantial resources to protect their populations have been greatly affected. ${ }^{2}$ It is clear that our public health systems and capacities remain insufficiently prepared to prevent a localised outbreak from becoming a pandemic.

\section{Summary box}

- Effective access to, and use of, data by National Public Health Institutes (NPHIs) or their equivalent is a critical building block of national preparedness.

- To enhance NPHI functioning, it is essential that they are routinely monitoring a broad set of priority indicators that are selected to reflect the countryspecific context.

- NPHIs must also have the authority to be able to request quick sharing of data to and from public and private sector organisations during health emergencies since initiating lengthy processes to request data access after an outbreak has started results in substantial delays in outbreak detection and reporting.

- In light of the massive health and economic impacts of the COVID-19 pandemic, there must be concerted efforts to improve timely and transparent access of national governments and international agencies to information about localised infectious disease outbreaks.

Emerging infectious disease outbreaks are occurring frequently and there is now an undeniable urgency to improve preparedness before the next one strikes. ${ }^{3}$

It is understandable that those who have been working in the global health security domain, which refers to activities aimed at addressing transnational acute public health threats, are frustrated that their efforts to ring alarm bells about pandemic risk have not been given due attention. ${ }^{4}$ However, despite much room for improvement in the current global response to infectious disease outbreaks, there has been notable progress since the SARS-CoV-1 epidemic in $2003 .^{5}$ This includes adoption of the revised International Health Regulations (IHR), ${ }^{6}$ which are legally binding regulations (although lacking an enforcement mechanism) obligating governments to notify the WHO of events that may constitute 
a public health emergency of international concern, ${ }^{7}$ which China did for COVID-19 on 31 December 2019.

The IHR, with 196 countries as signatories, represent a global agreement to work together to strengthen global health security. The IHR recognise the potential impact of infectious disease outbreaks on travel and trade and are intended to ensure that the response to outbreaks is proportionate to the level of risk they present, aiming to support effective action, while minimising wider economic impact. For COVID-19, the impact on travel and trade is already evident with the estimated costs running to trillions of dollars. ${ }^{8}$ Ebola, SARS and Zika also had substantial economic impacts linked to travel and trade restrictions. ${ }^{9-11}$ The World Bank estimates that affected West African countries lost US $\$ 6.8$ billion in gross domestic product as a result of the Ebola outbreak, and even sub-Saharan African countries that did not experience Ebola cases lost US\$550 million. ${ }^{12}$

\section{STRENGTHENING NATIONAL ACCOUNTABILITY FOR PREPAREDNESS}

In terms of identifying who should coordinate the IHR capacity assessments at a national level, the IHR stipulates the creation of a National Focal Point, often sitting in the Ministry of Health or, where they are established, in the National Public Health Institute (NPHI). There has been widespread support for the formation and strengthening of NPHIs in all countries to provide focused, centralised leadership and coordination for preparedness, both in terms of national responses and coordination with international agencies. ${ }^{1314}$ Currently, there are NPHIs in 99 countries, and these typically work with National Ministries of Health with varying degrees of autonomy. ${ }^{15}$ Of 38 NPHIs who responded to a survey about their roles, 19 indicated that they were the IHR National Focal Point (N Squires, personal communication, 2020).

Strengthening national accountability for preparedness for global health security at the national level requires the clear allocation of a mandate for the role and appropriate institutional links and authority of NPHIs to collect and collate the relevant information to inform preparedness assessment. While the IHR and Joint External Evaluation (JEE) process (for more detail see box 1) provide a robust framework for assessing preparedness, appropriate and accurate metrics and access to the data to allow measurement are often not available. Analyses conducted by Chatham House and The Graduate Institute also identified that there are potential gaps in what the IHR framework covers-such as knowledge sharing during a public health emergency. The current debate between the USA and WHO about the sharing of COVID-19 information by China suggests that additional indicators might be needed as part of IHR assessments. ${ }^{1617}$

For NPHIs, or their equivalent, to function effectively in support of IHR compliance strengthening, it is necessary to understand whether they have the
Box 1 Initiatives to monitor preparedness

In 2016, following the Ebola outbreak, the WHO, in collaboration with the US-lead Global Health Security Agenda, introduced a Joint External Evaluation (JEE) process to evaluate IHR capacities every 5 years and develop action plans to address identified weaknesses. The JEE assessments are based on national and international subject experts reviewing self-reported data, followed by a country visit to agree on scoring on 19 technical areas. The success of the JEE process is in large part based on its development as a tool to inform national level preparedness - making risks clear to national policy makers so that they can invest appropriately to minimise risk. As of May 2020, 110 countries have completed the JEE process. ${ }^{29}$

The premise of JEEs is that countries' self-assessments track their own progress over time by establishing a national baseline for assessing subsequent improvement. However, concern has been expressed that JEE scoring has been inappropriately used to make comparisons between countries, out of context, at times leading to ill-informed and potentially misleading inferences. There is also the perception that published JEE scores have resulted in the naming and shaming of countries with lower scores, often entirely without merit. For example, the Global Health Security Index, which scores 195 countries' capacity to face infectious disease outbreaks, in part based on JEE assessments, ranks the USA in first place and Singapore at $24 / 195,{ }^{24}$ when the latter has had a much stronger and successful response to COVID-19. ${ }^{3}$

mandate, cross-sectoral reach and access to data to track preparedness. At its annual meeting in 2017, the International Association of National Public Health Institutes (IANPHI) agreed that assessing the ability of NPHIs to assess preparedness would be a useful exercise to inform its membership of the strengths and weaknesses of current approaches. ${ }^{18}$

\section{DATA SHARING WITH NPHIS AS A CRITICAL ELEMENT OF PREPAREDNESS}

Preparedness encompasses the knowledge, capacities and systems to effectively anticipate, respond to and recover from the impacts of likely, imminent, emerging or current

One Health approach $\quad \begin{aligned} & \text { Cross-border } \\ & \text { coordination }\end{aligned} \quad \begin{gathered}\text { Subnational level } \\ \text { systems }\end{gathered}$

Data held by separate government health agencies or vertical disease control programmes

Information in private healthcare facilities including clinics, hospitals and laboratories

Routine data collected at ports of entry (airports, land crossings etc)

Data collected for business purposes by travel and trade organisations

Research and monitoring data from academic and non-governmental organisations

Data generated or compiled by multilateral organisations or international funding agencies

Figure 1 Some of the diverse sources of data that National Public Health Institutes may need to access for preparedness (horizontal bars) and complexities that need to be considered when accessing the data (vertical arrows). 


\section{Box 2 Objectives and methods of our analysis}

The Strengthening National Accountability for Preparedness and Global Health Security project (SNAP-GHS) ${ }^{30}$ is the first multicountry systematic investigation of barriers faced by National Public Health Institutes (NPHIs) at three sequential stages:

1. Access relevant existing data within an appropriate timeframe;

2. Analyse, interpret and present data in a policy-relevant manner;

3. Initiate Action through established mechanisms of communication and response activities.

We conducted a collaborative study with NPHIs in Ethiopia, Nigeria and Pakistan and identified urgent actions for all countries to consider for mitigation of the continued risk from emerging infectious diseases. Adapting an established rapid situational analysis methodology, ${ }^{31}$ each NPHI's ability and capacity to Access, Analyse and initiate Action on data were assessed through triangulation of insights from a Delphi-structured Indicator prioritisation workshop, key informant interviews, a simulation exercise in which NPHIs attempted to collect data on priority indicators for improving their preparedness (see box 3 ) and a review of national legislation and other relevant documentation on health security and preparedness.

health emergencies. ${ }^{19}$ Effective access to, and use of, data by NPHIs is a critical building block of preparedness. ${ }^{20}$ This allows NPHIs to carry out their essential functions including detecting unusual spikes in illnesses early, assessing which ports of entry might need interventions and communicating information to relevant professionals and the public. Although there are now several tools that monitor and evaluate progress toward global health security and health systems strengthening-including the JEEs, the Sustainable Development Goals and the Performance of Veterinary Services tool-there are significant challenges to overcome for NPHIs to have timely access to data that they do not own (figure 1). On a technical level, access to data held by other organisations requires engagement of NPHI officials, usually trained in human healthcare or laboratory sciences, with managers working in sectors that are disconnected from human health, and it entails constant negotiation, management and drafting of agreements. On

Box 3 Approach used to identify priority indicators for preparedness from existing data

The Indicator Prioritisation Workshop held in each country involved 25-40 data experts from within and outside of the National Public Health Institute (NPHI). External experts represented port health authorities, private diagnostic laboratories, animal health agencies, non-governmental agencies working on cross-border issues, government statistics officers and the military. Applying an adapted Delphi methodology (publication forthcoming), participants worked through a list of approximately 100 individual indicators as part of a group of 6 to 8 and scored each one in terms of its importance for the NPHI to routinely monitor for preparedness. At the end of the workshop, 14-16 of the highest scoring indicators for preparedness were agreed on by the group as 'priority indicators'. This methodology is detailed in a forthcoming publication, and the priority indicators selected by each country are summarised below in table 1 . a political level, information about the number of infectious disease cases in a country or the route by which people have been infected can have huge economic and ethical consequences. It is perhaps unsurprising then that access to, and use of, existing sources of data that can provide valuable information for preparedness is suboptimal. We present results of our systematic, multicountry analysis of barriers to optimal access to, and use of, data for preparedness by NPHIs (box 2).

\section{PRIORITY INDICATORS IDENTIFIED THAT NPHIS SHOULD BE ACCESSING FOR IMPROVED PREPAREDNESS}

Analysis of priority indicators considered essential to monitor preparedness (see box 3 for details about the systematic approach used to identify indicators) identified two main findings: (1) the majority of priority indicators that local experts considered essential to monitoring preparedness are not routinely accessed by NPHIs; (2) priority indicators identified by experts differ significantly between countries, with limited overlap, as identified indicators reflected country-specific risk factors for infectious disease emergence or spread.

In all three countries, it was agreed that NPHIs should have better access to data on:

1. Timeliness of reporting of disease information by subnational units such as states or provinces.

2. Subnational units' ability to respond to disease outbreak or disaster events.

3. The availability or functionality of an e-surveillance or online reporting mechanism at the subnational level.

4. The percentage of private healthcare facilities or private laboratories that report into a government information system.

\section{CHALLENGES WITH TIMELY ACCESS TO PRIORITY INDICATOR DATA}

Our simulation exercise-based assessment revealed that there could be long delays in accessing data on priority indicators to detect or respond to an outbreak. NPHI staff typically have multiple roles, and finding appropriate staff able to dedicate time to routinely collecting data from a range of organisations-although considered important—was challenging.

Data collection can take considerable time; even with good country commitment to the collection process, it sometimes took 3-6 weeks to access indicator data that was not already held by NPHIs. A large component of this delay was due to lack of clarity on which external agencies hold priority indicator data and who is responsible for authorising data sharing. NPHIs typically do not have the authority to oblige external organisations to share their data, even in the case of an emergency. National agencies (such as vertical disease control programmes and port authorities) and international agencies (such as the WHO and Food and Agricultural Organization) require different levels of formal requests before they can share data with NPHIs. 
Table 1 Summary of priority indicators selected by each country

\section{Prioritised indicators}

\begin{tabular}{|c|c|}
\hline Eth & \\
\hline 1 & Number of climate information centres established \\
\hline 2 & $\begin{array}{l}\text { Proportion of community Disaster Risk Response (DDR) committees/task force established members who have } \\
\text { improved their technical capacity on Disease Risk Management (DRM) system }\end{array}$ \\
\hline 3 & Proportion of regions that have coordination for an established and been supported in mainstreaming DRM \\
\hline 4 & Proportion of health facilities that report health service data to government reporting system \\
\hline 5 & Institutionalised and functional data quality assurance mechanism at (all) administrative levels \\
\hline 6 & $\begin{array}{l}\text { Yearly routine data quality assessment report that demonstrates improvement in data quality (timeliness, accuracy } \\
\text { and completeness of reports) including Expanded Programme of Immunization (EPI) data }\end{array}$ \\
\hline 7 & $\begin{array}{l}\text { Proportion of health administration levels with functional Surgical Information Systems (SIS) by category (Wordea } \\
\text { Health Office (WorHO), Zonal Health Department (ZHD), Regional Health Bureau (RHB)) }\end{array}$ \\
\hline 8 & $\begin{array}{l}\text { Proportion of health facilities that meet the National Health Information System (HIS) infrastructure standard by } \\
\text { category and ownership }\end{array}$ \\
\hline 9 & $\begin{array}{l}\text { Proportion of health Institutions with functional e-HMIS (health management information system) by category } \\
\text { (Health Centre, Hospital, WorHO, ZHD, RHB) }\end{array}$ \\
\hline 10 & HIS governance in place including e-Health \\
\hline 11 & $\begin{array}{l}\text { Legislation (approved by parliament) governing the collection, processing and dissemination of health information in } \\
\text { place }\end{array}$ \\
\hline 12 & National data repository and data warehouse \\
\hline 13 & Proportion of reported outbreaks or rumours verified and investigated by Woreda Health Office \\
\hline 14 & Proportion of health facilities submitting daily or weekly surveillance reports on time to the district \\
\hline 15 & Number of Internally Displaced Persons (IDPs) for climate-induced reasons \\
\hline 16 & Livestock vaccinations among households who own livestock by place of residence \\
\hline
\end{tabular}

\section{Nigeria}

$1 \quad$ Percentage of Local Government Areas (LGAs) that submit timely monthly surveillance reports

2 Proportion of healthcare workers trained/sensitised on Integrated Disease Surveillance and Response (IDSR) in the preceding year

3 Percentage of deaths due to notifiable communicable diseases

$4 \quad$ Yellow fever immunisation coverage

$5 \quad$ Percentage of states that timely submit disease surveillance reports

$6 \quad$ Full immunisation coverage

$7 \quad$ Maternal mortality rate

8 Percentage of private health providers participating in the Nigeria HMIS

9 (a) Community health extension workers (CHEWs) and (b) Junior CHEWs density per 10000 population

10 Percentage of outbreak alerts investigated within 48 hours

11 Proportion of healthcare facilities with basic water supply

12 Percentage of health facilities that provide minimum health package

13 Percentage of federal budget allocated to the health sector

14 Percentage of state budget allocated to the health sector

\begin{tabular}{cl} 
Pakistan & \\
\hline 1 & Percentage of districts submitting online routine monthly reports to provinces, within agreed timelines \\
\hline 3 & $\begin{array}{l}\text { Percentage of reporting units achieving satisfactory Data Quality Assurance (DQAS) score/mark increased } \\
4\end{array}$ \\
\hline 5 & $\begin{array}{l}\text { Percentage of private sector hospitals and healthcare facilities regularly reporting using Pakistan Health Information } \\
\text { Number of districts preparing annual health plans of actions considering the health issues emerging from the } \\
\text { information system }\end{array}$ \\
\hline
\end{tabular}




\begin{tabular}{ll}
\hline Table 1 & Continued \\
\hline & Prioritised indicators \\
\hline 6 & Is there a policy or strategy that makes specific reference to social media use in the health domain? \\
7 & Is there a national policy or strategy on the use of social media by government organisations? \\
8 & Is there a national Electronic Health Record (EHR) system? \\
\hline 10 & Percentage of primary care facilities with EHR \\
\hline 11 & Is there a National Laboratory Information System? \\
\hline 12 & Is there a National Pathology Information System? \\
\hline 14 & Total agricultural exports (US\$) \\
\hline 15 & Percentage of districts with their recognised surveillance sites having functional online surveillance for vaccine \\
\hline 16 & Number of individuals returning from Provinces of Pakistan \\
\hline
\end{tabular}

Limitations in the coverage, accuracy, timeliness and completeness of electronic data collection systems are a further challenge. Lack of mechanisms for receiving data from private healthcare providers, which often greatly outnumber government healthcare facilities, is also a widespread issue. Variations in the strength of infectious disease reporting systems across states or districts, as well as notable differences in capacity for data management across regions, mean that there is variability in quality, completeness and timeliness of reporting from subnational units. Thus, if an outbreak originates in a district with limited capacity to detect and report cases to the NPHI in a timely manner, this will impede appropriate action at a national level and delay reporting to the WHO under IHR.

Finally, substantial human resource engagement is required to gather data on priority indicators. This includes junior and mid-level staff from NPHIs to conduct visits or calls to organisations that own the priority indicator data and several hours of senior staff time to arrange formal data request letters and ensure that protocols for contacting external agencies are in place.

\section{CONCERNS ABOUT USE OF DATA BY NPHIS}

For accessing data from agencies working outside of public health-such as animal health agencies, airports and statistics departments-having a clearly defined and formally endorsed mandate for the NPHI is helpful in initiating a discussion on data sharing. A lack of clarity about how data will be used can be a deterrent to data sharing. This could be addressed by a two-way commitment for timely data sharing to be matched by prompt analysis and feedback. There is a particular challenge collecting data from private sector organisations, such as commercial diagnostic laboratories and airlines, which are conscious that compiling and sharing data have a cost that needs to be justified in terms of understanding how the data will be used and of any resulting benefits from the data generated. Data sharing may also be resisted because of the risk of highlighting weaknesses in data quality or, in the case of private sector providers, because insights from the data about levels of activity may be considered commercially or financially sensitive. Some of these concerns will be addressed if the NPHI has a strong reputation and a clear mandate for data collection and analysis in the national interest, which requires transparency over how data will be used to enhance preparedness.

Timeliness of data analysis by NPHIs is a key determinant in willingness of organisations to share priority indicator data. Overall, there is a demand for more insights and recommendations from NPHIs when there is a disease outbreak rather than just information on numbers of new cases; such real-time analysis and syntheses of data require substantial resources and experienced data analysts within NPHIs, especially during outbreak periods when resources are stretched. The dependence of some NPHIs on international technical agencies for support on sophisticated analysis of data for preparedness may be problematic. Another common challenge is generating analysis that is useful for agencies working in animal health and presenting recommendations that are relevant to private sector organisations such as hotels and hospitals; NPHIs were expected to produce materials that were tailored not only to public health bodies but to a range of sectors.

\section{CONCLUSION}

The current COVID-19 health emergency serves as a glaring reminder of how essential it is to have effective subnational and national data sharing systems to support preparedness, as local actions directly affect the magnitude of health and economic impacts globally. At the start of the COVID-19 outbreak in China, for example, critical delays in local officials notifying national authorities may have led to the proliferation of cases and independent chains of transmission. ${ }^{21}$ Delays in NPHIs, and therefore national governments and international public health agencies, accessing relevant information about 
infectious disease outbreaks can result in substantial morbidity and mortality globally_and yet we have not acted to address these delays. ${ }^{22}$ Furthermore, there are already discussions about whether the resources being mobilised for COVID-19 will be wasted because the capacities are not in place in countries to build and implement evidence-based response strategies; continued failure to strengthen national public health response mechanisms such as those coordinated by NPHIs may therefore impede resource generation. ${ }^{23}$

It has been argued that there is a need for an independent global mechanism for monitoring preparedness, ${ }^{24}$ and the Global Preparedness Monitoring Board was established by WHO, World Bank and others in $2018^{25}$ to act as an independent monitoring and advisory body. However, there is a danger in creating a monitoring mechanism that conducts global comparisons, as countries may be less willing to engage if they think it might be a vehicle to criticise rather than support them. Thus, there are advantages to avoiding international country comparisons and focusing on strengthening national accountability for preparedness by building the capacity of national institutions to assess preparedness using measures relevant to their own contexts across the full range of IHR competencies. ${ }^{26}$

This is the first assessment, to our knowledge, of practical challenges affecting timely access to, and use of, data that is critical to preparedness by NPHIs. Judging by the (reported) challenges experienced with timely data sharing for COVID-19 management in diverse settingsfrom South Korea to the USA-the issues we engage with are salient in many countries. ${ }^{27}{ }^{28}$ Our findings suggest that NPHIs need to urgently be equipped with the mandate, expertise and resources to carry out a broader role in preparedness. Such a role necessitates collection and analysis of data from multiple sources that do not routinely share data with public health authorities. To enhance NPHI functioning, it is essential that they are routinely monitoring a broad set of priority indicators that are selected to reflect the country-specific context.

NPHIs must also have the authority to be able to request quick sharing of data from public and private sector organisations during health emergencies and to access additional human and financial resources during disease outbreaks. Having a clear legal mandate that supports the role of NPHIs is critical, since personal relationships and individual leadership cannot be relied on in the long-term. Initiating a lengthy, formal process to request data sharing after an outbreak has started could result in unacceptable delays.

Preparedness at a national level, which is critical to prevent future pandemics, is dependent on the availability of robust information systems that allow relevant data to be collected, shared and analysed sufficiently rapidly to inform a timely local response. NPHIs in many countries have a significant role in preparedness, detection and response but may lack a sufficiently strong mandate to collect all the data from outside of human
Box 4 Steps that can be taken to enhance the role of NPHls in preparedness

1. National Public Health Institutes (NPHIs) need a well-defined legal mandate for public health preparedness to enable them to access relevant preparedness indicators that are held externally. Formal agreements (eg, Memorandum of Understanding) for data sharing are required urgently for NPHIs to obtain data from non-health and private sector entities, such as airports, private healthcare facilities and animal-based food producers.

2. To fulfil a role in preparedness requiring coordination across sectors, senior staff in NPHls need expertise that are much broader than clinical and laboratory sciences; they need to be adept at organisational and emergency management, One Health, surveillance and data analysis. They need access to expertise for developing and reviewing data sharing agreements.

3. Timely, transparent and informative communication of synthesised data from NPHIs will facilitate sustained data sharing with NPHIs. External organisations were encouraged to share data with NPHIs if they were aware of how their data was used.

health that is needed for monitoring preparedness. Through our situational analysis, we identified steps that could be taken to support the important role of NPHIs in national preparedness (box 4).

Twitter Mishal S Khan @DrMishalK and Lara Hollmann @lara_hollmann

Acknowledgements This research was conducted as part of the Strengthening Accountability and Preparedness for Global Health Security (SNAP-GHS) project. We a grateful for input from the following NPHIs: Ethiopian Public Health Institute, Pakistan's National Institute of Health, Nigeria Centre for Disease Control, Public Health England, Robert Koch Institute, Norwegian Institute of Public Health and the Netherlands National Institute for Public Health and the Environment. We also acknowledge the International Association of National Public Health Institutes (IANPHI) for their advice and support during the project.

Contributors MK, NE, OD, Cl, Al, NS and EO conceptualised the study. MK, NE, AR$\mathrm{S}, \mathrm{LH}, \mathrm{EA}, \mathrm{TRR}$ and $\mathrm{OU}$ implemented the study. MK developed the first draft of the paper. All authors contributed to writing and finalising the manuscript.

Funding The SNAP-GHS project was funded by Public Health England.

Competing interests None declared.

Patient consent for publication Not required.

Provenance and peer review Not commissioned; externally peer reviewed.

Data availability statement All data relevant to the study are included in the article or uploaded as supplementary information.

Open access This is an open access article distributed in accordance with the Creative Commons Attribution Non Commercial (CC BY-NC 4.0) license, which permits others to distribute, remix, adapt, build upon this work non-commercially, and license their derivative works on different terms, provided the original work is properly cited, appropriate credit is given, any changes made indicated, and the use is non-commercial. See: http://creativecommons.org/licenses/by-nc/4.0/.

\section{ORCID iD}

Lara Hollmann http://orcid.org/0000-0002-5500-8275

\section{REFERENCES}

1 Heymann DL, Shindo N, WHO Scientific and Technical Advisory Group for Infectious Hazards. COVID-19: what is next for public health? Lancet 2020;395:542-5.

2 Day M. Covid-19: surge in cases in Italy and South Korea makes pandemic look more likely. BMJ 2020;368:m751. 
3 Legido-Quigley H, Asgari N, Teo YY, et al. Are high-performing health systems resilient against the COVID-19 epidemic? Lancet 2020;395:848-50.

4 McCloskey B, Dar O, Zumla A, et al. Emerging infectious diseases and pandemic potential: status quo and reducing risk of globa spread. Lancet Infect Dis 2014;14:1001-10.

5 Kandel N, Chungong S, Mahjour J. Improvement in annual report of self-assessments to the International health regulations (2005). Wkly Epidemiol Rec 2019;94:iii-vii.

6 World Health Assembly. International health regulations (2005). Geneva, 2006. Available: http://site.ebrary.com/id/10161481

7 Fidler DP, Gostin LO. The new international health regulations: an historic development for international law and public health. J Law Med Ethics 2006;34:85-94.

8 Hutt R. The economic effects of COVID-19 around the world. world Econ. forum. Available: https://www.weforum.org/agenda/2020/ 02/coronavirus-economic-effects-global-economy-trade-travel [Accessed 5 May 2020].

9 Huber C, Finelli L, Stevens W. The economic and social burden of the 2014 Ebola outbreak in West Africa. J Infect Dis 2018;218:S698-704.

10 Food and Agricultural Organization. Impact of the Ebola virus disease outbreak on market chains and trade of agricultural products in West Africa. Washington, DC, 2016.

11 Joppe M. Trapped tourists: how is the coronavirus affecting travel? World Econ. Forum. Available: https://www.weforum.org/agenda/ 2020/02/the-coronavirus-will-hit-the-tourism-and-travel-sector-hard/ [Accessed 5 May 2020].

12 Thomas MR, Smith G, Ferreire FHG, et al. The economic impact of Ebola on sub-Saharan Africa: updated estimates for 2015. Washington, DC, 2015. Available: http://documents.worldbank.org/ curated/en/541991468001792719/The-economic-impact-of-Ebolaon-sub-Saharan-Africa-updated-estimates-for-2015

13 Koplan JP, Dusenbury C, Jousilahti P, et al. The role of national public health Institutes in health infrastructure development. BMJ 2007;335:834-5.

14 Frieden TR, Koplan JP. Stronger national public health Institutes for global health. Lancet 2010;376:1721-2.

15 International Association of National Public Health Institutes. About IANPHI, 2020. Available: www.ianphi.org/whoweare/index.html [Accessed 5 May 2020].

16 Leigh J, Moon S, Garcia E, et al. Is global capacity to mange outbreak improving?: an analysis, 2018.

17 The Economist. Daily Chart: China's data reveal a puzzling link between covid-19 cases and political events, 2020. Available: https://www.economist.com/graphic-detail/2020/04/07/chinas-datareveal-a-puzzling-link-between-covid-19-cases-and-political-events

18 Chatham House. One health: developing indicators to monitor progress toward implementation, 2017. Available: www. chathamhouse.org/event/one-health-developing-indicators-monitorprogress-toward-implementation [Accessed 5 May 2020].

19 World Health Organization. A strategic framework for emergency preparedness. Geneva, 2016. Available: https://apps.who.int/ iris/bitstream/handle/10665/254883/9789241511827-eng.pdf? sequence $=1$

20 Bloland P, Simone P, Burkholder B, et al. The role of public health institutions in global health system strengthening efforts: the US CDC's perspective. PLoS Med 2012;9:e1001199.

21 Huang C, Wang Y, Li X, et al. Clinical features of patients infected with 2019 novel coronavirus in Wuhan, China. Lancet 2020;395:497-506.

22 Morse SS. Global infectious disease surveillance and health intelligence. Health Aff 2007;26:1069-77.

23 Lange JE. Despite coronavirus alarm Bells, global health security remains Underfunded, 2020. Available: https://unfoundation.org/ blog/post/despite-coronavirus-alarm-bells-global-health-securityremains-underfunded/

24 Center for Health Security. Global health security index: building collective action and accountability. Baltimore, 2019.

25 Global Preparedness Monitoring Board. A world at risk: annual report on global preparedness for health emergencies. Geneva, 2019.

26 Verrecchia R, Dar O, Mohamed-Ahmed O, et al. Building operational public health capacity through collaborative networks of national public health Institutes. BMJ Glob Health 2019;4:e001868.

27 Gander K. Coronavirus Cases Tested in U.S. Removed From CDC Website, According to Congressman: 'American People Deserve Answers'. Newsweek, 2020. Available: https://www.newsweek.com/ coronavirus-cases-tested-us-removed-cdc-website-accordingcongressman-american-people-1490158

28 Mahbubani $R$. The leader of a fringe religious sect at the center of South Korea's coronavirus outbreak has apologized as Seoul's mayor files a lawsuit accusing the group of 'murder' and 'injury'. Bus. Insid, 2020. Available: https://www.businessinsider.com/southkorea-seoul-mayor-sues-shincheonji-coronavirus-outbreak-leaderapologizes-2020-3? $r=U S \& I R=T$

29 World Health Organization. JEE Dashboard, 2020. Available: https:// extranet.who.int/sph/jee-dashboard [Accessed 5 May 2020].

30 Chatham House. Strengthening national accountability and Prepardness for global health security (SNAP-GHS), 2020. Available: https://www.chathamhouse.org/about/structure/ global-health-security/strengthening-national-accountability-andpreparedness-global-health-security-snap-ghs [Accessed 5 May 2020].

31 Khan MS, Schwanke-Khilji S, Yoong J, et al. Large funding inflows, limited local capacity and emerging disease control priorities: a situational assessment of tuberculosis control in Myanmar. Health Policy Plan 2017;32:ii22-31. 